\title{
POR UMA HISTÓRIA DA FILOSOFIA DA EDUCAÇÃO DE JACQUES MARITAIN
}

Névio de Campos*

RESUMO: O problema deste artigo é discutir a origem dos escritos pedagógicos e alguns elementos da filosofia da educação de Jacques Maritain, privilegiando uma análise de natureza histórica (contextos de produção) e filosófica (análise das ideias pedagógicas). Apoia-se na discussão da História Intelectual para reconstituir os contextos da intervenção de Maritain, assim como a sua produção pedagógica cuja síntese encontra-se na obra Rumos da Educação.

Palavras-chave: História intelectual; História dos intelectuais; filosofia da educação; pensamento católico; Jacques Maritain.

RESUMEN: El problema de este artículo es discutir el origen de los escritos pedagógicos y algunos elementos de la filosofía de la educación de Jacques Maritain, privilegiando un análisis de naturaleza histórica (contextos de producción) y filosófica (análisis de las ideas pedagógicas). Se apoya en la discusión de la Historia Intelectual para reconstituir los contextos de intervención de Maritain, así como su producción pedagógica - cuya síntesis se encuentra en la obra Rumos da Educação.

Palabras claves: Historia intelectual, historia de los intelectuales, pensamiento católico, filosofía de la educación, Jacques Maritain.

\section{Introdução}

A origem do presente texto tem relação direta com pesquisas produzidas em torno da organização do movimento intelectual católico no Paraná, entre o final do século XIX e a primeira metade do século XX. Em nossas análises predominam investigação a respeito da constituição de um grupo de intelectuais, detentor de capital cultural e político, que trabalha em defesa do projeto institucional da Igreja Católica, criando um conjunto de aparatos intelectuais. Nesse percurso analítico, privilegiamos aspectos da História Intelectual e da História dos Intelectuais, pois tanto trouxemos a baila elementos do pensamento produzido e reproduzido pelo laicato paranaense quanto da rede de organização e sociabilidade dessas personagens.

\footnotetext{
* Doutor em Educação pela UFPR, Professor do Programa de Pós-Graduação em Educação da Universidade Estadual de Ponta Grossa (Paraná). Email: ndoutorado@yahoo.com.br.

CAMPOS, Névio de. Por uma história da filosofia da educação de Jacques Maritain. Revista Sul-Americana de Filosofia e Educação. Número 18: maio-out/2012, p. 199-221.
} 
No plano intelectual, particularmente no processo de filiação filosófica, o laicato católico paranaense organizou encontros ordinários e extraordinários no Círculo de Estudos Bandeirantes ${ }^{1}$, durante a década de 1930, assim como atividades na Faculdade de Filosofia, Ciências e Letras do Paraná ${ }^{2}$, a partir da década de 1940, para promover reflexões de natureza diversa, entre elas, discussões de caráter filosófico. Nesses momentos foi recorrente a referência à matriz filosófica norteadora da organização do pensamento católico no Paraná. Em nossas interlocuções com as fontes foi possível observar que, na década de 1930, os teóricos utilizados e citados como intérpretes do tomismo no Paraná foram o Cardeal Mercier e o próprio Alceu Amoroso Lima. Já, a partir da década de 1940, ganha destaque Jacques Maritain, pois é o que atesta a sentença de Homero de Barros (1946, p. 40): "Maritain frisa o caráter teocêntrico do humanismo, para que este [...] não [se] confunda com o humanismo do Renascimento ou com o da Reforma, que foram antropocêntricos por excelência".

Tais observações indicam que a produção intelectual, isto é, um referencial doutrinário católico circulava entre o laicato paranaense. No entanto, os autores e as obras que circulavam sofriam mutação de acordo com as mudanças internas da Igreja Católica e do campo intelectual de um modo geral. A identificação dessa relação do laicato católico com um referencial doutrinário é a razão principal de escrita deste texto, cujo objetivo é analisar alguns aspectos do pensamento educacional de Jacques Maritain.

Nesses termos, o presente texto tem por objetivo discutir alguns aspectos da filosofia da educação de Jacques Maritain, enfatizando o contexto da sua produção e a própria concepção de educação católica defendida por esse filósofo. Nesse sentido, esta abordagem inscreve-se na História Intelectual - cuja especialidade tem um sentido multidisciplinar, pois está na interface da Filosofia, Sociologia e História. A rigor, conforme observações de Helenice Rodrigues da Silva, "[...] a História Intelectual oscila, por um lado, entre uma Sociologia, uma História e até mesmo uma biografia dos intelectuais, e por outro, entre uma análise das obras e

\footnotetext{
${ }^{1}$ CEB - criado em 1929 por onze fundadores, constituído por dez leigos e um padre.

${ }^{2} \mathrm{FFCL}$ - criada em 1938. A partir de 1939 passou a ser controlada diretamente pelos Irmãos Maristas.
} 
das ideias como, por exemplo, uma possível versão da história da filosofia" (RODRIGUES DA SILVA, 2003, p. 16).

Nessa ambiência teórica insere-se o problema deste artigo, pois pretende discutir a origem dos escritos pedagógicos e a própria filosofia da educação de Maritain. Pelo exposto, está explícita que a pretensão é uma análise de natureza histórica (contextos de produção) e filosófica (análise das ideias pedagógicas de Maritain). Desse modo, o percurso analítico segue duas direções: primeira, dialoga com a produção intelectual, buscando reconstituir os principais interlocutores de Maritain; segunda, analisa diretamente a produção teórica de Jacques Maritain, principalmente a obra Rumos da Educação, na qual ele sistematizou suas reflexões a respeito da filosofia da educação. Em termos mais precisos, a primeira discussão far-se-á a partir da produção acadêmica. Já a segunda, trata-se de uma análise diretamente das ideias de Maritain.

\section{Origem dos escritos pedagógicos de Maritain}

Jacques Maritain é filósofo. Em sua trajetória intelectual esteve ocupado com debates pertinentes aos mais diversos aspectos da filosofia, particularmente com metafísica, estética, ética e política. Além disso, envolveu-se com os problemas específicos da educação. Entretanto, é possível afirmar que, grande parte de suas obras, não tratam diretamente da educação. Por outro lado, o livro Rumos da educação expressa sua principal contribuição à filosofia da educação católica. Tal hipótese pode ser localizada no prólogo dessa obra quando Maritain sustenta que "ninguém se admirará, portanto, de que este esboço de uma filosofia da educação se apresente numa perspectiva americana" (MARITAIN, 1968, p. 15).

O livro Rumos da Educação foi traduzido no Brasil em 1947. Entre 1947 e 1968 teve cinco edições ${ }^{3}$. O fato de ser traduzido no Brasil em 1947 indica a quase imediata circulação dessa produção de Maritain nas terras tupiniquins, pois a publicação em inglês (original) aconteceu em 1943 nos Estados Unidos. A primeira edição publicada no Brasil corresponde a uma parte da quinta edição publicada

\footnotetext{
${ }^{3}$ Edições de Rumos da educação no Brasil: $1^{a}$. Edição, 1947; 2a ., 1959; $3^{\mathrm{a}}$., 1963, 4ª ., 1966, $5^{\mathrm{a}}$. 1968. Este texto trabalha com a $5^{a}$. Edição.
} 
em 1968. A primeira edição publicou o texto intitulado "A educação na encruzilhada dos caminhos", cujo texto é resultado de conferências promovidas na Universidade de Yale. A editora dessa Universidade publicou-as em 1943, cuja versão também foi traduzida para o francês em 1947. Outra parte de Rumos da educação trata-se do ensaio "Visão tomista da educação", publicado originalmente no Anuário da Sociedade Nacional para o Estudo de Educação de Chicago, em 1955. Conforme Maritain, esse ensaio constituiu-se em um capítulo do anuário que versava a respeito da filosofia moderna e educação. Por fim, o terceiro ensaio "Sobre alguns aspectos típicos da educação cristã" - resulta de uma conferência pronunciada no Colégio Diocesano Kent School, em 1955, e publicado pela Editora da Universidade de Yale, em 1957 "num volume coletivo intitulado The Christian Idea of Education" (Idem).

Charles Journet ao prefaciar a primeira edição (1947) na França, faz uma síntese que especifica a origem do texto "Education at the crossroads". Ele observa que "Education at the crossroads, publicado pela primeira vez em [agosto] de 1943 e reimpresso duas vezes depois [outubro 1943; julho 1944] é o texto de quatro conferências pronunciadas durante a guerra na Universidade de Yale, nos Estados Unidos" (JOURNET, 1968, p. 21). Mais adiante, Journet adverte a respeito do efeito de sentido que as reflexões de Maritain lhe provocaram ao lê-las pela primeira vez: “[...] - foi em Roma em outubro de 1945 - tivemos a impressão de ter encontrado finalmente [...] o pequeno tratado de filosofia da educação, baseado nos dados de Santo Agostinho e de Santo Tomás de Aquino, que há tanto tempo procurávamos (JOURNET, 1968, p. 22).

Avança Journet ao observar:

Impressionaram-nos imediatamente a segurança excepcional das distinções que aí eram propostas, a fecundidade de suas exposições sumárias, a clareza de suas definições, a riqueza das soluções que oferecia a questões que nos haviam sido muitas vezes apresentadas, e sobretudo a perícia dos resumos e a maneira perfeitamente simples com que o autor abordava as questões mais essenciais (JOURNET, 1968, p. 22-23). 


\section{Revista Sul-Americana de Filosofia e Educação - RESAFE}

As discussões a respeito dos problemas da educação aconteceram no período em que Maritain residiu e ensinou nas universidades norte-americanas ${ }^{4}$. Por isso, a assertiva no prólogo de Rumos da Educação, de que trata-se de um ensaio em uma perspectiva americana. Ele chama a atenção para a diferença entre as experiências educacionais da França e dos Estados Unidos ao destacar que "o leitor francês ficará um tanto desconcertado, pois o sistema educacional americano é profundamente diferente do francês" (MARITAIN, 1968, p. 16). Ele assevera que a diferença pode ser observada "tanto em sua estrutura geral quanto no fato que a maioria dos colégios e universidades são estabelecimentos livres do controle do Estado, mantidos por fundos particulares e possuindo cada qual fisionomia, espírito e fins característicos bem distintos" (Idem).

Maritain destaca que nos Estados Unidos há forte relação entre pensamento educacional e projeto democrático. Segundo ele, "tornou-se uma espécie de axioma comumente reconhecido pelo pensamento americano que o progresso da educação é essencial à existência de uma sociedade democrática" (Ibidem). Entretanto, assevera o autor, "o que é menos conhecido - e que mereceria um estudo especial - são as várias aventuras (às vezes desastrosas, como no tempo em que reinava [...] o pragmatismo dos discípulos de Dewey em pedagogia” (Ibidem). Essas observações indicam que a filosofia pragmática consistia em uma das tradições filosóficas e pedagógicas contra as quais o pensamento católico confrontava-se. Por outro lado, Maritain ressaltava a existência de uma autocrítica na tradição intelectual norte-americana, ao mencionar a importância de ser estudada "a ardente autocrítica feita, em nome da sabedoria filosófica e dos 'grandes livros' que testemunham a 'grande convenção' a que se subordina a cultura do Ocidente" (Ibidem). Ele destaca as intervenções de Robert Hutchins (Presidente da Universidade de Chicago), Mortimer Adler e de John Nef, também dessa Universidade. Desse último, contemporâneo de Maritain, destaca a tentativa de “associar as 'artes liberais' $e$ as humanidades aos estudos científicos $e$

\footnotetext{
${ }^{4}$ Maritain viveu entre 1940 e 1960 nos Estados Unidos. Ele foi obrigado a deixar a França, pois sua esposa Raissa e a cunhada Vera eram judias. Além disso, ele estava deveras engajado na resistência francesa contra o avanço do fascismo na França.
} 
tecnológicos", assim como a lutar "contra os perigos da especialização" e pelo retorno, "sob nova forma, a uma educação e a uma cultura autenticamente humanistas" (MARITAIN, 1968, p. 17). É interessante observar que Maritain enfatiza as intervenções de Hutchins, Adler e Nef na Universidade de Chicago, criando um efeito de sentido de destituição da tradição inaugurada por John Dewey, isto é, ao indicar que a Universidade de Chicago é um dos principais ambientes de contraposição ao cientificismo e tecnicismo, Maritain procura relativizar a importância da filosofia pragmática - cujo nascimento deu-se nessa instituição universitária.

No próprio prólogo é possível perceber a referência de Maritain a efervescência intelectual dos Estados Unidos que exigia uma posição da tradição católica no campo pedagógico: "devido às circunstâncias em que os estudos sobre educação aqui publicados foram escritos, e do caráter concreto e prático de seu assunto, a perspectiva deste trabalho deveria ser uma perspectiva americana" (Idem). Não obstante, o autor relativiza esse caráter histórico ao destacar que "em compensação, os princípios filosóficos que procuramos também focalizar têm por si um valor e um alcance universais". Para ele, "se são verdadeiros e baseados na razão, como acreditamos, exigem sua aplicação, sob modalidades apropriadas, ao sistema de nosso país como a qualquer outro sistema educacional” (Idem). A rigor, conforme Cândido Rodrigues, "a produção dos escritos de Jacques Maritain devem ser interpretados dentro do contexto da sua divergência com o mundo moderno, com a ciência e a filosofia modernas e, ao mesmo tempo, de sua percepção dos avanços desse mesmo mundo moderno" (RODRIGUES, 2009, p. 11). Pelo exposto é possível sustentar que as discussões de Maritain buscavam contrapor-se ao projeto filosófico e pedagógico postulado pelos diferentes modelos teóricos do século XX, assim como sistematizar uma filosofia da educação que coadunasse os princípios da democracia aos preceitos católicos.

\section{Os sete erros da educação moderna}

No item anterior a preocupação foi a de indicar a origem dos textos de filosofia da educação de Jacques Maritain. Agora, a principal pretensão é a de 
discutir alguns aspectos da própria filosofia da educação defendida por esse filósofo, procurando pensá-la na relação e contraposição ao projeto da "educação nova' ou 'escola ativa' ou ainda 'escola nova', advogada pelos teoristas, desde o último quartel do século XIX" (MONARCHA, 2009, p. 23). Em termos analíticos, neste item faremos um percurso por entre as ideias educativas ou por entre Rumos da educação de Maritain, enfatizando a crítica ao pensamento pedagógico moderno.

A obra Rumos da educação é bastante complexa, pois além de expressar a maturidade da trajetória de Maritain, tem mais de 300 páginas, nas quais discute os erros da educação moderna e postula os princípios de uma filosofia da educação católica. De acordo com o autor, "esta obra sobre educação compõe-se de vários estudos, escritos em datas diferentes" (MARITAIN, 1968, p. 15). Na primeira parte deste texto já indicamos precisamente as datas das três partes da obra. O ensaio que resultou de várias conferências cujo título é "A educação da encruzilhada dos caminhos" constitui a primeira parte do livro, dividida em quatro capítulos $^{5}$. Já a segunda parte da obra é formada pelos outros dois ensaios "Visão tomista da educação" (primeiro capítulo) e "Sobre alguns aspectos típicos da educação cristã" (segundo capítulo). Além desses ensaios, a edição brasileira incorporou o texto escrito por Maritain para a tradução francesa ${ }^{6}$, cujo título é "O problema da escola pública na França" (anexo). Para fins específicos de nossa discussão serão privilegiadas algumas partes da obra, particularmente as que tratam dos fins da educação (capítulo primeiro).

A discussão a respeito dos fins da educação principia pelo problema da natureza humana e educação, pois Maritain contrapõe-se a tendência que reconhece apenas a existência das condições sociais e históricas do homem, embora ele não desconsidere os axiomas da História e da Sociologia. Além disso, ele critica a concepção abstrata de ser humano, cuja origem encontra-se na filosofia de Platão. Na avaliação do autor, "a tarefa da educação não se reduz a formar essa abstração que é o homem platônico, mas uma determinada criança,

\footnotetext{
${ }^{5}$ Fins da educação (capítulo um); O dinamismo da educação (capítulo dois); As humanidades e a educação liberal (capítulo três); As experiências da educação contemporânea (capítulo quatro).

${ }^{6} \mathrm{~A}$ tradução no Brasil foi feita da versão francesa "Pour une philosophie de l'education.
} 
pertencendo a uma determinada nação, a um meio social e momento histórico dados" (MARITAIN, 1968, p. 25). Entretanto, assevera que "antes de ser uma criança do século XX, americana, europeia, dotada ou retardada, é ela um descendente do homem" (Idem). Assim sendo, "a tarefa principal da educação é primeiramente formar o homem, dirigir o desenvolvimento dinâmico pelo qual ele vem a ser homem. Eis a razão por que poderíamos intitular estas páginas: A educação do homem" (MARITAIN, 1968, p. 26).

Ora, se o fim da educação é educar o homem, sem distinguir as condições históricas e sociais, a proposição de Maritain funda-se em uma antropologia filosófica, pois reconhece uma condição universal na humanidade. Nesse sentido, a educação deve dar prevalência ao que é da essência do homem e relativizar o que é acidental. Essa visão antropológica justifica sua cruzada contra os defensores da educação nova, educação ativa ou escola nova. No entanto, é importante destacar que sua visão universalista de homem e educação não implica no desconhecimento das condições culturais da vida humana, pois é o que atesta a assertiva de que o homem "é também um animal de cultura, cuja espécie só poderá subsistir com o progresso da sociedade, da civilização. É um animal histórico: daí a multiplicidade dos tipos culturais ou ético-históricos que diversificam a humanidade" (Idem).

O fim da educação é conformar em cada homem o caráter da humanidade. Essa condição primeira, na avaliação de Maritain, tem um sentido reduzido ou descaracterizado entre as filosofias da educação da modernidade. De acordo com ele, as filosofias modernas retiram a importância dos fins da educação, isto é, há um esvaziamento das causas primeiras e últimas. A rigor, ele destaca que o primeiro erro consiste na ignorância dos fins. Para o autor, "o primeiro é o esquecimento ou a ignorância dos fins. Se os meios são apreciados e cultivados por si, por sua própria perfeição e não só enquanto meios, deixam de levar ao fim" (MARITAIN, 1968, p. 27-28). Em termos mais precisos, ele assevera que "esta supremacia dos meios sobre o fim e o desmoronamento consecutivo de todo propósito seguro e eficácia real parecem ser a principal censura que podemos fazer à educação contemporânea". Na sua avaliação, "seus meios não são maus, ao 
contrário, geralmente melhores do que os da velha pedagogia. O mal está justamente em serem tão bons, que somos levados a perder de vista o fim" (MARITAIN, 1968, p. 28). A crítica é endereçada às vertentes teóricas decorrentes do movimento científico, particularmente das diferentes tendências da Psicologia. Ele adverte que "a criança é de tal maneira submetida a testes, tão observada, suas necessidades tão especificadas, os métodos para tudo lhe facilitar na vida tão aperfeiçoados, que a finalidade de todos esses benefícios [...] corre o risco de ser esquecida ou desprezada" (Idem). Tal advertência não implica na descaracterização da contribuição da ciência, pois é o que atesta a sentença a seguir: "o progresso científico dos meios e métodos pedagógicos é evidente, mas, quanto maior sua importância, tanto maior é a exigência de reforço paralelo da sabedoria prática e da tendência dinâmica para um fim” (MARITAIN, 1968, p. 29).

Se o primeiro erro é a negação dos fins ou a tomada dos meios como fins, o segundo equívoco é uma falsa compreensão do que sejam os fins da educação. Na primeira posição, Maritain ataca a herança da Psicologia - cuja lógica é garantir os meios adequados para o processo educativo. Já, na segunda, contrapõe-se a própria concepção científica positivista - cujo pressuposto consistiria em estabelecer os fins da educação, considerando o ser humano apenas na sua condição fenomênica, isto é, física, biológica e histórica. Desse modo, no entendimento de Maritain, a Psicologia transformou os meios em fins da educação, portanto, não há fins na tradição dessa área do conhecimento. Por outro lado, a ciência empírica assume uma função - definir os fins da educação - que não é de sua competência. Observemos a assertiva desse filósofo: "o segundo erro geral não consiste no esquecimento da finalidade, mas em idéias falsas ou incompletas relativas à própria natureza do fim" (MARITAIN, 1968, p. 28). Nesse aspecto, Maritain repõe a disputa entre Filosofia e Ciência, particularmente ao asseverar que:

Se a tarefa da educação é ajudar e guiar a criança à sua realização humana, não poderá furtar-se aos problemas $e$ dificuldades da Filosofia, pois supõe por natureza uma filosofia do homem e, antes de tudo, é obrigada a responder 


\section{Revista Sul-Americana de Filosofia e Educação - RESAFE}

à pergunta que lhe faz a Filosofia: Que é o homem? (MARITAIN, 1968, p. 29).

Por definição devolve à filosofia o papel de definição dos fins da educação, pois tal postulado supõe a inquirição de quem seja o homem - indagação peculiar da antropologia filosófica. Entretanto, Maritain não sustenta o saber filosófico como único a contribuir nesse aspecto. Para ele, "[...] somente duas classes ou categorias de noções relativas ao homem merecem ser consideradas como 'honestas' ou 'retas', a saber: a concepção científica e a filosófico-religiosa" (Idem). Essas duas formas de compreender o homem operam em condições distintas, pois "a concepção puramente científica do homem tende somente a coligir dados que possa medir e observar, e é levada a não considerar o ser ou a essência”. Já, a posição da filosofia católica "é ontológica. Não é inteiramente verificável pela experiência sensível. Ocupa-se com os caracteres essenciais e intrínsecos (mas invisíveis, intangíveis) e com o conteúdo inteligível desse ser que é chamado de homem" (MARITAIN, 1968, p. 29-30).

Maritain reconhece a contribuição da ciência tal qual propugnou o Círculo de Viena, embora condene a pretensão reducionista de conhecimento promovida pelos filósofos neopositivistas. A rigor, o movimento neopositivista "quer defender uma filosofia antimetafísica, estreitamente ligada às ciências da natureza, à lógica $e$ à matemática. Porém, pretende ser igualmente um movimento militante que vai combater o idealismo" (LACOSTE, 1998, p. 40). Em termos precisos, esses filósofos não negam os conhecimentos filosóficos ou metafísicos, apenas relegam a outra instância do saber. Sem dúvida, ao sustentarem que "as proposições, os enunciados da metafísica, nem mesmo são falsos como podem ser as lendas; não têm sentido porque não podem ser objeto de uma verificação empírica" (Idem), os integrantes do Círculo de Viena criam um efeito de sentido menor ao saber filosófico - portanto, destituem a Filosofia do direito de dizer o que são as coisas.

Maritain organiza a sua filosofia em interlocução com a filosofia moderna. Essa relação dialógica pode ser observada quando ele afirma: "é evidente que a concepção puramente científica do homem fornecerá dados inestimáveis e sempre novos em relação aos meios e instrumentos educacionais" (MARITAIN, 1968, p. 


\section{Revista Sul-Americana de Filosofia e Educação - RESAFE}

30). Entretanto, ele também sistematiza seu pensamento em contraposição à filosofia moderna, pois "por si só [a concepção científica] não poderá fornecer nem os primeiros fundamentos, nem as direções primordiais da educação, pois este necessita conhecer inicial e primordialmente o que é o homem, qual a sua natureza e qual a escala de valores que ela implica" (Idem). Ele arremata que "a concepção puramente científica, porque ignora 'o ser enquanto tal', não conhece tais coisas mas somente aquilo que o ser humano manifesta no domínio da observação sensorial e da medida" (Idem).

Assim, podem-se visualizar as possibilidades e os limites da concepção puramente científica enumerados por Maritain. Cabe agora analisar os argumentos utilizados pelo filósofo francês para justificar a prevalência da concepção filosóficoreligiosa no processo de constituição de uma filosofia da educação. Já de início ele destaca que "se nos propusermos basear a educação e o êxito de sua obra unicamente na concepção científica do homem, não poderíamos senão deformar, falsear essa concepção”. Observemos que o debate de Maritain dá-se no campo da própria lógica, pois "sendo obrigado a responder à questão sobre a natureza e o destino do homem, seria preciso extrair dela, isto é, da idéia científica, uma espécie de metafísica, o que é inteiramente contrário à sua estrutura típica" (MARITAIN, 1968, p. 31). As consequências dessa tentativa trariam problema no plano lógico e na esfera prática. Em primeiro lugar, "o resultado sob o ponto de vista lógico, seria uma metafísica espúria, disfarçada em ciência e desprovida de toda luz filosófica". Por outro lado, "do ponto de vista prático, seria um repúdio ou então uma idéia errônea dessas mesmas realidades e valores, sem o que a educação perde toda significação humana, tornando-se o adestramento de um animal em proveito do Estado" (Idem).

Após destituir qualquer possibilidade de existência da metafísica na concepção puramente científica, Maritain assume como pressuposto racional que é necessário uma concepção completa e integral de homem. Na sua avaliação, tal modelo seria expresso pela concepção filosófico-religiosa. Entendamos o sentido dessa proposição: "Filosófica porque tem por objeto a natureza ou essência do homem; religiosa por causa do modo de existir da natureza humana em relação a 


\section{Revista Sul-Americana de Filosofia e Educação - RESAFE}

Deus, e por causa dos dons especiais, das provações e da vocação implicados nesse modo de existir" (Idem). Ao defender sua proposição como filosófica, alinhase a tradição iniciada na Grécia, portanto vincula seu pensamento aos principais problemas da filosofia, entre eles os problemas ontológicos, principalmente a definição do homem enquanto ser. Já ao anexar o substantivo religioso a concepção filosófica, insere-se na tradição judaico-cristã, para a qual há uma visão providencialista da história humana.

A tradição filosófica foi fortemente atacada pelo pensamento moderno - a ponto de Hannah Arendt sustentar que "[...] no decorrer de toda a era moderna, não se pode negar que a sua influência e a sua importância diminuírem como nunca antes. Não foi no pensamento da Idade Média, mas no da era moderna, que a filosofia passou a segundo ou mesmo terceiro plano" (ARENDT, 2004, p. 307). Em terminologia mais assustadora, ela afirma que "depois que Descartes baseou sua filosofia nas descobertas de Galileu, a filosofia parece condenada a seguir sempre um passo atrás dos cientistas e de suas descobertas". Ou ainda em tom mais aterrorizador, "os filósofos tornaram-se epistemologistas, preocupados com uma teoria global da ciência da qual os cientistas não necessitavam" (Idem). Nesse sentido, a posição de Maritain é de defesa do saber filosófico em contraposição ao pensamento científico - movimento que contou com intervenções de inúmeros filósofos do século XX que filiavam-se em diferentes tradições teóricas, como, por exemplo, E. Husserl, M. Heidegger, M. Ponty, H. G. Gadamer, A. Camus, J. P. Sartre, M. Foucault, T. Adorno, J. Habermas.

Não obstante, a intervenção de Maritain filia-se a uma concepção metafísica muito específica - metafísica católica. Nesse aspecto, a cruzada desse filósofo é em defesa também da tradição cristã, pois propala uma concepção cristã de homem. $\mathrm{Na}$ avaliação desse autor, os sentidos dessa concepção de homem devem-se ao fato de "ser esta a verdadeira [concepção], e não pelo fato de estar nossa civilização impregnada dela". Além disso, "o homem de nossa civilização é o homem cristão mais ou menos laicizado" (MARITAIN, 1968, p. 32). Ele propõe que os povos busquem um assentimento comum em torno dessa filosofia moral (concepção cristã de homem). Esse filósofo destaca que um assentimento completo 
não é possível, pois há grupos ou civilizações que proferem outras experiências, embora justifique essa impossibilidade "não por falta de provas objetivas da razão, mas devido à pobreza inerente à inteligência humana" (Idem).

Ele proclama que a comunhão das tradições judaico-greco-cristã "torna possível a uma filosofia cristã da educação, se bem fundamentada e racionalmente desenvolvida, desempenhar um papel inspirador no concerto, mesmo em relação àqueles que não participam da crença de seus adeptos” (MARITAIN, 1968, p. 33). Ao associar as três tradições, consideradas as raízes da civilização ocidental, Maritain promove a filosofia católica como síntese integradora dos povos do século $\mathrm{XX}$, isto é, a dilacerada civilização ocidental poderá ser regenerada pela filosofia cristã. É com esse sentido que ele apresenta uma sintética concepção de homem. Em primeiro lugar recupera a definição grega ao sustentar que "o homem é um animal racional, cuja suprema dignidade está na inteligência”. Em seguida, restaura a acepção judaica, para a qual o homem é "um indivíduo livre em relação pessoal com Deus, cuja suprema 'justiça' ou integridade está na obediência voluntária à Sua lei". Por fim, a definição cristã: "uma criatura pecadora e ferida, chamada à vida divina e à liberdade da graça, e cuja suprema perfeição consiste no amor" (Idem).

A palavra-chave dessas concepções seria pessoa humana, detentora de inteligência e vontade, pois "não existe apenas como ser físico. Há na carne e nos ossos do homem uma alma que é um espírito e que vale mais do que todo o universo físico. O espírito é a raiz da personalidade" (MARITAIN, 1968, p. 34). Aqui prevalece o sentido peculiar da filosofia de Maritain, não apenas em afirmar a existência da alma, mas em sustentar a concepção cristã de alma, pois proclama como "lugar de habitação de Deus e criada para a vida eterna" (Idem). Nesse aspecto, recupera o sentido clássico da metafísica. Dessa forma, inscreve-se na contraposição à filosofia moderna que tinha a "preocupação exclusiva com o ego, em oposição à alma ou à pessoa ou ao homem em geral" (ARENDT, 2004, p. 266). Ou ainda, em contraposição a "uma tentativa de reduzir todas as experiências, com o mundo e com outros seres humanos, a experiências entre o homem e si mesmo" (Idem). 
Feitas as devidas ponderações em relação ao que denominou concepção puramente científica e ao proclamar a concepção filosófico-religiosa como filosofia da educação do século XX, Maritain apresenta que a finalidade da educação:

É guiar o homem no desenvolvimento dinâmico no curso do qual se constituirá como pessoa humana - dotada das armas do conhecimento, do poder de julgar e das virtudes morais transmitindo-lhe ao mesmo tempo o patrimônio espiritual da nação $e$ da civilização às quais pertence e conservando a herança secular das gerações (MARITAIN, 1968, p. 36-37).

Tal definição tem a pretensão de devolver à filosofia a função de formular os fins da educação - pois eles estão associados a uma indagação própria da antropologia filosófica - Quem é o homem?

Outro combate da filosofia de Maritain é contra o pragmatismo. Segundo ele, "o pragmatismo é o terceiro erro que encontramos em nosso caminho. Insistir sobre a importância da ação, da 'práxis', é coisa excelente, pois viver é agir. Mas a ação e a prática tendem a um fim, e fim determinante sem o que perdem elas sua direção" (MARITAIN, 1968, p. 39). Aqui, um dos problemas é de ordem de definição de verdade, pois o pragmatismo assume outro pressuposto de verdade. $\mathrm{Na}$ avaliação de Richard Rorty, os pragmáticos "não precisam nem de uma metafísica, nem de uma epistemologia. Eles visualizam a verdade como, na frase de William James, o que é bom para nós acreditarmos" (RORTY, 2002, p. 39, grifo no original). Por outro lado, é possível afirmar que o pensamento de Maritain é herdeiro de duas outras definições de verdade: verdade como correspondência e verdade revelada, as quais estão fundamentadas em ideias metafísicas. Para Rorty, os pragmáticos "não carecem de uma avaliação da relação entre crenças e objetos chamada "correspondência'" (Idem). No contexto da filosofia norte-americana do século XX, o pragmatismo tinha forte reverberação. O principal embate promovido pelos pragmáticos pode ser sintetizado na afirmação de Rorty: "a tradição da cultura ocidental, centrada na noção de busca pela verdade, a tradição que corre desde os filósofos gregos e atravessa o lluminismo, é o exemplo mais claro da tentativa de encontrar um sentido para a existência em direção à objetividade" (RORTY, 2002, p. 37). 
A crítica de Maritain ao pragmatismo dá-se nos planos da filosofia pura e da filosofia da educação. Em primeiro lugar, sustenta que "é um menosprezo infeliz definir o pensamento humano como um órgão de resposta aos estímulos $e$ situações atuais do meio" (MARITAIN, 1968, p. 40). Por outro lado, assevera que "toda idéia humana - para ter um sentido - deve atingir de certo modo aquilo que as coisas são ou em que consistem" (Idem) ${ }^{7}$. Nesse ponto, o filósofo francês opera no campo da metafísica e da epistemologia - aspectos irrelevantes ao pragmatismo, conforme vimos anteriormente. Em sentido rigoroso, na metafísica católica o homem consiste em Deus, isto é, o homem é redutível a Deus, portanto, a concepção de conhecimento não pode ser reduzida à razão pragmática, pois "o pensamento humano é uma intuição espiritual; o ato de pensar começa não só com dificuldades mas por visadas e termina com visadas que são estabelecidas verdadeiras pela demonstração racional ou pela verificação experimental" (Ibidem). Sua crítica lógica é arrematada ao proferir que "a ação humana está baseada na verdade apreendida por si mesma, a verdade por amor da verdade. Sem fé na verdade não há eficiência humana. Tal é, a nosso ver, a crítica principal que deve ser feita à teoria pragmatista do conhecimento" (Idem).

No plano da educação, as implicações do pragmatismo representam a instrumentalização do ensino e da aprendizagem. Para Maritain, "a pedagogia moderna fez progressos inestimáveis insistindo sobre a necessidade de analisar cuidadosamente o sujeito humano e de não o perder de vista". Entretanto, "o erro começa quando o objeto a ensinar e sua primazia são esquecidos e quando o culto dos meios - não pelo fim mas sem o fim - resulta numa espécie de adoração

\footnotetext{
${ }^{7}$ Observemos que no texto de Maritain há alusão aos problemas da metafísica e ontologia. A rigor, duas perguntas podem ser respondidas pela ontologia: quem existe? Que é consistir? "Para a primeira, existem múltiplas e variadas respostas [eu existo, o mundo existe, Deus existe, as coisas existem]. As respostas que se dão à pergunta quem existe? constituem a parte da ontologia que se chama a metafísica. A metafísica é aquela parte da ontologia que se encaminha a decidir quem existe, ou seja, quem é o ser em si, o ser que não é em outro, que não é redutível a outro; a parte da ontologia que responde ao problema da existência, da autêntica e verdadeira existência, da existência em si, ou seja, à primeira pergunta. Para a segunda pergunta existem também múltiplas respostas possíveis [nem eu, nem as coisas existem, mas as coisas e eu estamos em Deus, portanto, todos consistimos, salvo Deus, que não consiste, visto que não é redutível a outra coisa]. Essas múltiplas respostas possíveis são outras tantas maneiras de consistir. Os objetos consistem nisso ou naquilo, e cada um consiste segundo a estrutura de sua objetividade. A segunda pergunta dá, pois, lugar a uma teoria geral dos objetos, de qualquer objeto, da objetividade em geral" (MORENTE, 1980, p. 64).
} 
psicológica do sujeito" (MARITAIN, 1968, p. 41). Nessa discussão, o filósofo tomista reafirma sua convicção da primazia do espiritual. Em termos ontológicos é possivel sublinhar que os homens e as coisas consistem. E Deus existe. Essa condição dá primazia ao espiritual em relação ao mundo material. Em razão de os homens estarem em Deus, implica "na aspiração da pessoa humana à liberdade, $e$, antes de tudo, à liberdade interior e espiritual" (Idem). A primazia do espiritual não representa a negação do material, pois "a segunda forma essencial desse desejo é o da liberdade exteriormente manifestada" (Ibidem), na vida societária. Nesse sentido, a função da educação é preparar o homem para viver a condição social da humanidade, mas principalmente formar a pessoa humana na vida pessoal e no progresso espiritual. No campo educacional, o pragmatismo teve em Dewey sua principal expressão, "um teorista que ingressara na psicologia pela filosofia" (MONARCHA, 2009, p. 37). A educação tinha em Dewey um sentido diferente daquele requerido por Maritain, pois "o objeto da educação é o homem, que, por viver num mundo em permanente mudança (i. é., a América industrial), não poderia deixar de empreender a contínua 'reconstrução da experiência vital"" (MONARCHA, 2009, p. 38). Conforme Carlos Monarcha, a doutrina de Dewey "implantou-se duradouramente na cultura norte-americana, por ter acolhido na reflexão psicopedagógica a recusa veemente do dualismo clássico que opunha o espírito ao mundo, o pensamento à ação" (Idem).

Ao combater o pragmatismo por meio da primazia do espiritual, Maritian avizinha-se do quarto erro da educação moderna - o sociologismo. A origem dessa vertente está em Durkheim, para quem "o homem que a educação deve realizar, em cada um de nós, não é o homem que a natureza fez, mas o homem que a sociedade quer que ele seja; e ela o quer conforme o reclame a sua economia interna, o seu equilíbrio" (DURKHEIM, 1978, p. 81). Maritain, por sua vez, combate a máxima de Durkheim ao proferir que "a essência da educação não consiste em adaptar um futuro cidadão às condições e interações da vida social, mas primeiramente em formar um homem - e, por aí preparar um cidadão" (MARITAIN, 1968, p. 43). A principal razão de discussão entre Maritain e o que ele denomina de sociologismo é o problema dos fins da educação, pois para Durkheim 
(1978, p. 88) “os fins da educação são sociais". Por outro lado, para Maritain (1968, p. 46) "a teoria pragmatista só pode subordinar e escravizar a educação às tendências que se desenvolvem na vida coletiva da sociedade". Em razão disso, sustenta Maritain (Idem.) que "o objetivo final da educação - realização do homem como pessoa humana - é infinitamente mais elevado e mais vasto".

Outro empreendimento de Maritain no campo pedagógico é o combate ao intelectualismo - cujas expressões ele localiza na pedagogia clássica e na pedagogia científica. Na primeira ele observa um projeto educacional fundamentado na retórica; na segunda prevalece uma visão educativa fundada na formação técnica $e$ especializada em detrimento da formação humanista e universal. Sua crítica principal é endereçada à segunda tendência do intelectualismo, pois sua manifestação histórica é a expressão do que ele denominou de concepção puramente científica. Em relação a esse equívoco no campo educacional ele profere que "um programa de educação que apenas visasse formar especialistas, teria como resultado, verdadeiramente falando, a animalização progressiva da mente e da vida humana. O culto excessivo da especialização desumaniza a vida do homem" (MARITAIN, 1968, p. 48). Um dos seus argumentos de contraposição ao intelectualismo científico tem caráter político, pois sustenta que em uma democracia há necessidade de espíritos com formação universal, o que garantiria um "governo do povo, pelo povo e para o povo" (MARITAIN, 1968, p. 49). Para ele, seria impensável uma democracia com uma educação de caráter especializado, pois "a concepção democrática da vida exige primordialmente uma educação liberal para todos e um desenvolvimento humanista geral da sociedade toda" (Idem).

Outro equívoco presente na educação, na avaliação de Maritain, é o voluntarismo - que consiste na reação contra o intelectualismo, isto é, a primazia da vontade, cuja origem está em Schopenhauer. Esse filósofo tomista reconhece a importância de considerar a vontade no campo pedagógico. No entanto, ele combate os usos dessa vertente no contexto dos fascismos. A posição de Maritain é de que "a inteligência, em si, é mais nobre do que a vontade, pois sua atividade é mais imaterial e universal. Mas pensamos também que, quanto às coisas e objetos 
sobre os quais se exercem nossas atividades, é melhor amar o bem do que simplesmente conhecê-lo" (MARITAIN, 1968, p. 52). De tal observação depreende-se que Maritain postula o que denomina educação integral - formação da inteligência e da vontade, embora reitere que "a formação da vontade é certamente mais importante para o homem do que a formação do intelecto" (Idem).

O último erro da educação identificado por Maritain consiste na assertiva de que tudo pode ser aprendido. Nas palavras desse filósofo, "é um erro muito freqüente no mundo moderno - aquele que consiste em crer que tudo pode ser aprendido" (MARITAIN, 1968, p. 53). Em contraposição ao avanço das inúmeras funções atribuídas aos colégios e universidades, particularmente a formação profissional, Maritain chama a atenção do papel moral da educação escolar, pois defende a importância da prudência como elemento formativo que consiste na "capacidade interior e vital de discernimento desenvolvido no espírito e apoiado numa vontade bem dirigida" (MARITAIN, 1968, p. 54). Ele destaca que a educação escolar deverá concorrer para a formação moral, entretanto, observa que esse aspecto perpassa por todas as experiências formativas. Ele reitera que a educação escolar não poderá reduzir o fim da educação à formação profissional e inserção dos indivíduos à sociedade, mas sim concorrer para conformar o que ele chama de verdadeira finalidade da educação - a educação moral - aquela que "desempenha um papel essencial na educação da escola e da universidade, e importa que esse papel seja mais e mais acentuado" (MARITAIN, 1968, p. 58). Para Maritain, a máxima tudo pode ser ensinado é um paradoxo da educação moderna. Nesse aspecto, ele sustenta que a solução consiste naquilo que é o mais importante para a formação do homem: "a retidão da vontade e a aquisição da liberdade interior, bem como o estabelecimento de uma sã relação com a sociedade" (MARITAIN, 1968, p. 60).

Nessa parte do texto, procuramos discutir alguns aspectos da filosofia da educação de Maritain, enfatizando sua contraposição aos principais sistemas pedagógicos modernos. Nesse sentido, a intervenção desse filósofo tomista pode ser interpretada como um dos sistemas intelectuais cujo objetivo "é estabelecer 
uma ordem gnosiológica" (BOURDIEU, 2002, p. 9, grifo no original). Nesse sentido, as produções intelectuais ou "os 'sistemas simbólicos' cumprem a sua função política de instrumentos de imposição ou de legitimação da dominação" (BOURDIEU, 2002, p. 11), podendo contribuir para o domínio de uma filosofia sobre as outras. Em palavras mais precisas, os diferentes grupos sociais estão envolvidos "[...] numa luta propriamente simbólica para imporem a definição do mundo social mais conforme aos seus interesses, e imporem o campo das tomadas de posições ideológicas reproduzindo em forma transfigurada o campo das posições sociais" (Ibidem).

Nesses termos, entendemos que o conceito de campo mostra-se fecundo para compreender o sentido dos escritos de Maritain, pois "um campo, e também o campo científico, se define entre outras coisas através da definição dos objetos de disputas e dos interesses específicos que são irredutíveis aos objetos de disputas e aos interesses próprios de outros campos" (BOURDIEU, 1983, p. 89). Em sentido mais específico, "para que um campo funcione, é preciso que haja objetos de disputas e pessoas prontas a disputar o jogo, dotadas de habitus que impliquem o conhecimento e o reconhecimento das leis imanentes do jogo, dos objetos de disputas etc." (Idem). Essa disputa é o que procuramos indicar nesse percurso da trajetória de Maritain, pois "a luta interna do campo é pela conquista $e$ administração do poder simbólico, definido como o poder de constituir o dado pela enunciação, de fazer ver e fazer crer, e, deste modo, a ação sobre o mundo, portanto, o mundo" (BOURDIEU, 2002, p. 15).

No plano intelectual havia um espaço de luta pelo domínio do poder simbólico, isto é, pela definição do próprio campo cultural, assim como pela definição do mundo social. No campo filosófico as controvérsias eram intensas, pois "a filosofia do século XX apresenta tudo, menos um quadro harmônico. As posições básicas de alguns filósofos do século XX encontram-se entre si em rígida, e até inconciliável oposição" (FLEISCHER, 2000, p. 11). É possível afirmar que os problemas que norteavam os diferentes filósofos do século $\mathrm{XX}$ tinham origens semelhantes. Nesse sentido, pactuamos com a observação de Margot Fleischer (2000, p. 12-13): 


\section{Revista Sul-Americana de Filosofia e Educação - RESAFE}

Os filósofos do século XX, tanto por seu pensamento como por suas atividades e seus destinos pessoais, têm múltiplas implicações com as situações e acontecimentos de seu tempo. Sua 'situação espiritual' é essencialmente codeterminada pelos efeitos dos patronos filosóficos do século XIX, pelo desenvolvimento das ciências e da técnica no século XX, pelos acontecimentos da época, sobretudo por suas fases calamitosas, bem como pela forma de vida $e$ sistema de pensamento da moderna sociedade industrial. Muitos deles, enquanto filósofos, responderam a essa situação de forma histórico-crítica e consciente da crise.

Sem entrar na polêmica do impacto do pensamento de Maritain na filosofia contemporânea, pois certamente outras vertentes teóricas tiveram maior reverberação nos meios intelectuais, é possível interpretar a intervenção desse filósofo tomista no terreno da disputa intelectual e política. É nessa direção que discutimos o confronto de Maritain a psicologia empírica, ao neopositivismo, pragmatismo, sociologismo, intelectualismo e voluntarismo, pois tais tendências apresentam, na avaliação desse filósofo, as sínteses do que ele denominou sete erros da educação moderna.

Não obstante a luta travada no campo de produção cultural, uma vez que "cada campo é dotado de um móvel de disputa específico e tem uma história própria, que permite apreender a sua relativa autonomia em relação aos outros campos" (BONNEWITZ, 2003, p. 62), as intervenções de Maritain tiveram profunda ressonância nos demais campos sociais, pois "os campos não são espaços com fronteiras estritamente delimitados, totalmente autônomos. Eles se articulam entre si” (Idem). É em razão da importância que o intelectual assumirá no "século dos intelectuais" (WINOCK, 2000) que os homens das letras passaram a ganhar espaço em outros campos sociais. Ou na denominação de Bourdieu, é com o processo de autonomia do campo intelectual que os letrados passam a promover intervenções no campo político. Segundo Bourdieu, "é só no final do século [XIX], no momento em que o campo literário, o campo artístico e o campo científico acedem à autonomia, que os agentes mais autónomos destes campos autónomos podem intervir no campo político enquanto intelectuais" (BOURDIEU, 1996, 382). 


\section{À guisa de conclusões}

A pretensão deste texto não consiste nem a fazer apologia de uma concepção puramente científica, nem a defesa de uma concepção filosóficoreligiosa. Essa observação não é petição de um princípio de neutralidade, pois no campo intelectual não há análises destituídas dos valores. Porém, temos convicção que é dever de um pesquisador buscar reconstituir determinados debates sem a pretensão tão somente de emitir um julgamento moral.

Não há dúvida de que temos nossas convicções - por vezes passíveis de serem identificadas na forma de organização desta narrativa - mas procuramos, neste artigo, escrever uma história intelectual da filosofia da educação de Jacques Maritain com a intenção de contribuir ao debate filosófico e histórico. Nesse percurso, privilegiamos os aspectos atinentes ao contexto de produção dos escritos educativos desse filósofo tomista, muito embora tenhamos deixado de abordar os aspectos da trajetória formativa de Maritain, particularmente sua adesão ao cristianismo (conversão), bem como filiação e rompimento com a Ação Francesa. Em grande medida, essa ausência justifica-se pelo recorte do problema deste artigo, mas principalmente pela complexidade desses elementos da trajetória de Maritain para serem tratados em um texto com intensa limitação de espaço. Em razão disso, enfatizamos o contexto de disputa no campo de produção cultural, no qual estava envolvido Maritain, isto é, privilegiamos o contexto das ideias pedagógicas e/ou do campo intelectual. Desse modo, esta narrativa está recortada por uma acepção muito particular de contexto, pois ao reconstituir o lugar da produção dos escritos pedagógicos de Maritain fez a opção por considerar a própria obra (Rumos da educação) como referência para precisar o contexto das ideias desse filósofo tomista. Em outros termos, procuramos depreender a partir dessa obra quais eram os principais interlocutores de Maritain, isto é, que intelectuais e projetos teóricos e/ou filosóficos estavam sendo combatidos por esse pensador católico.

A opção por definir o contexto a partir da fonte de análise é uma condição fundamental à análise da História da Filosofia e da própria História Intelectual, pois o percurso analítico faz-se na relação complexa entre os pressupostos conceituais 
do pesquisador e as afirmações presentes na fonte de pesquisa. Por outro lado, temos convicção que essa acepção de contexto tem suas fragilidades, pois o lugar de produção de escritos filosóficos não esgota-se no que está no próprio texto. É em razão disso que indicamos acima a necessidade de abordar o pensamento pedagógico de Maritain no conjunto de suas obras, assim como analisar suas obras no interior do movimento do campo religioso, particularmente das mudanças ocorridas no interior da Igreja Católica na segunda metade do século XX. Além disso, é fundamental problematizar as relações entre os diferentes campos sociais como constituintes dos contextos de produção dos escritos desse filósofo católico. Porém, tais indicações representam as lacunas deste artigo, as quais poderão ser minimizadas com outras pesquisas.

Portanto, nossa preocupação foi trazer a baila alguns elementos do papel do filósofo no "século dos intelectuais", enfatizando os debates pedagógicos de Maritain em defesa da filosofia a partir da noção de campo de produção cultural como lócus de poder e de luta pelo monopólio do poder simbólico e, por conseqüência, de disputa pelo poder de agir e intervir no mundo social. Em sentido estrito, buscou-se compreender a intervenção de Jacques Maritain no campo da filosofia da educação, privilegiando os contextos de produção de seus escritos pedagógicos (História Intelectual e/ou História dos Intelectuais) e a natureza de suas ideias educativas (História da Filosofia da Educação).

\section{Referências bibliográficas}

BARROS, Homero Batista de. Preleção inaugural do ano letivo de 1946, na Faculdade de Filosofia, Ciências e Letras do Paraná: formação humanística. Anuário da Universidade do Paraná, Curitiba, s. n., p. 40-46, 1946.

BONNEWITZ, Patrice. Primeiras lições sobre a sociologia de P. Bourdieu. Petrópolis: Vozes, 2003.

BOURDIEU, Pierre. As regras da arte: gênese e estrutura do campo literário. São Paulo: Companhia das Letras, 1996.

. Questões de sociologia. Rio de Janeiro: Marco Zero, 1983.

O poder simbólico. Rio de Janeiro: Bertrand Brasil, 2002.

DURKHEIM, Emille. Educação e sociologia. São Paulo: Melhoramentos; Rio de Janeiro: Fundação Nacional de Material Escolar, 1978. 
FLEISCHER, Margot. (Org.). Filósofos do século XX. São Leopoldo: Unisinos, 2000.

JOURNET, Charles. Prefácio à primeira edição francesa. In: MARITAIN, J. Rumos da educação. Rio de Janeiro: Agir, 1968, p. 21-24.

LACOSTE, Jean. A filosofia no século XX. Campinas: Papirus, 1998.

MARITAIN, Jacques. Rumos da educação. Rio de Janeiro: Agir, 1968.

MONARCHA, Carlos. Brasil arcaico, escola nova: ciência, técnica e utopia nos anos 1920-1930. São Paulo: Unesp, 2009.

MORENTE, Manuel. Garcia. Fundamentos de filosofia: lições preliminares. São Paulo: Mestre Jou, 1980.

RODRIGUES, Cândido Moreira. Da Ação Francesa ao humanismo integral: o filósofo Jacques Maritain na França das décadas de 1920 a 1940. Contemporâneos - Revista de Artes e Humanidades, n. 4, p. 1-18, maio-out. 2009.

RODRIGUES DA SILVA, Helenice. A história intelectual em questão. In: LOPES, M. A. (Org.). Grandes nomes da história intelectual. São Paulo: Contexto, 2003, p. $15-24$.

RORTY, Richard. Objetivismo, relativismo e verdade: escritos filosóficos I. Rio de Janeiro: Relume-Dumará, 2002.

WINOCK, Michel. O século dos intelectuais. Rio de Janeiro: Bertrand Brasil, 2000.

Recebido em 06/03/2012

Aprovado em 08/04/2012 